\title{
Association of cognitive performance with interleukin-6 receptor Asp358Ala polymorphism in healthy adults
}

Daimei Sasayama ${ }^{\text {a b* }}$, Hiroaki Hori ${ }^{\text {a }}$, Toshiya Teraishi ${ }^{\text {a }}$, Kotaro Hattori ${ }^{\text {a }}$, Miho Ota ${ }^{\text {a }}$ Junko Matsuo $^{\text {a }}$, Yumiko Kawamoto ${ }^{\text {a, }}$ Yukiko Kinoshita ${ }^{\text {a }}$, Naoji Amano ${ }^{\text {b }}$, Hiroshi Kunugi a, c

a Department of Mental Disorder Research, National Institute of Neuroscience, National Center of Neurology and Psychiatry, 4-1-1, Ogawahigashi, Kodaira, Tokyo, 187-8502, Japan

${ }^{\mathrm{b}}$ Department of Psychiatry, Shinshu University School of Medicine, Matsumoto, 390-8621, Japan

${ }^{\mathrm{c}}$ Core Research of Evolutional Science \& Technology (CREST), Japan Science and Technology Agency (JST), Tokyo, 102-0075, Japan

*Correspondence to:

Daimei Sasayama

Department of Mental Disorder Research, National Institute of Neuroscience, National Center of Neurology and Psychiatry

4-1-1, Ogawahigashi, Kodaira, Tokyo, 187-8502, Japan

TEL: +81-42-341-2712, extension 5132

FAX: +81-42-346-1744

Email: sasayama@shinshu-u.ac.jp 


\begin{abstract}
Wechsler adult intelligence scale-revised was performed in 576 healthy adults to examine whether a functional polymorphism (Asp358Ala) of the IL-6 receptor (IL-6R) gene is associated with cognitive performance. Verbal intelligence quotient in Asp homozygotes was significantly higher compared to Ala carriers ( $\mathrm{P}=0.005)$. Compared to Ala carriers, Asp homozygotes performed better in the verbal subtests requiring long-term memory stores. Elevated IL-6 and soluble IL-6R levels in Ala carriers may have negative impact on acquiring verbal cognitive ability requiring long-term memory.
\end{abstract}

Key words: cognitive function; interleukin-6; genetic polymorphism; intelligence 


\section{Introduction}

Accumulating evidence has suggested a negative effect of interleukin-6 (IL-6) on learning and memory. Previous studies have shown that increased peripheral IL-6 levels are associated with age-related cognitive decline in well-functioning elders (Weaver et al. 2002; Yaffe et al. 2003; Lekander et al. 2011) as well as in patients with Alzheimer's disease (Huberman et al. 1995; Singh and Guthikonda 1997). Marsland et al (Marsland et al. 2006) have shown that higher plasma IL-6 levels are also associated with lower cognitive performance in healthy middle-aged adults. A brain imaging study has shown that peripheral IL-6 levels were found to be inversely associated with hippocampal grey matter volume in healthy adults (Marsland et al. 2008), further supporting the role of IL-6 on subclinical cognitive decline.

Animal studies have also shown an involvement of IL-6 in cognitive functioning. Studies using transgenic mice have reported that IL-6 deletion has a facilitatory effect on learning and memory (Braida et al. 2004) while chronic IL-6 expression from astrocytes in the brain results in a decline in avoidance learning performance (Heyser et al. 1997). These findings suggest that the persistence of excessive IL-6 signaling has a negative impact on the cognitive performance. Furthermore, some studies have shown that increased levels of hippocampal IL-6 interfere with long-term potentiation (LTP) (Bellinger et al. 1995; Tancredi et al. 2000).

A single nucleotide polymorphism (SNP) Asp358Ala (rs8192284) of the IL-6 receptor (IL-6R) gene, which substitutes an amino acid at the proteolytic cleavage site, is known to be strongly associated with the circulating levels of soluble IL-6R (sIL-6R) 
(Galicia et al. 2004; Rafiq et al. 2007; Reich et al. 2007; Sasayama et al. 2011b) and IL-6 (Rafiq et al. 2007; Reich et al. 2007; Jiang et al. 2010; Sasayama et al. 2011b). The Ala allele of this polymorphism is associated with increased levels of both IL-6 and sIL-6R, suggesting that possession of this allele may result in elevated levels of IL-6 signaling. The present study was aimed to examine the Asp358Ala polymorphism for association with cognitive functioning in healthy adults.

\section{Methods}

\subsection{Subjects}

Subjects were 576 healthy volunteers without current or past history of psychiatric treatment (144 males, average age \pm standard deviation (s.d.) $=41.7 \pm 16.3$ years; 432 females, $46.2 \pm 14.4$ ). All subjects were biologically unrelated Japanese. They were screened using the Japanese version of the Mini International Neuropsychiatric Interview (M.I.N.I.) (Sheehan et al. 1998; Otsubo et al. 2005) by a research psychiatrist. Participants were excluded if they had a prior medical history of central nervous system disease or severe head injury, or if they met the Diagnostic and Statistical Manual of Mental Disorders, $4^{\text {th }}$ edition criteria (American Psychiatric Association 1994) for substance abuse or dependence, dementia, or mental retardation. The study protocol was approved by the ethics committee at the National Center of Neurology and Psychiatry, Japan. After description of the study, written informed consent was obtained from every subject. 


\subsection{Assessment of cognitive functioning}

All participants were administered the Japanese version of Wechsler adult intelligence scale-revised (WAIS-R) (Wechsler 1981; Shinagawa et al. 1990) by a research psychologist.

\subsection{Genotyping}

Genomic DNA was prepared from the venous blood according to standard procedures. The Asp358Ala polymorphism was genotyped using the TaqMan 5'-exonuclease allelic discrimination assay (Applied Biosystems, Foster City; assay ID: AHD1C2X). Thermal cycling conditions for polymerase chain reaction were 1 cycle at $95^{\circ} \mathrm{C}$ for 10 minutes followed by 50 cycles of $92^{\circ} \mathrm{C}$ for 15 seconds and $60^{\circ} \mathrm{C}$ for 1 minute. The allele-specific fluorescence was measured with ABI PRISM 7900 Sequence Detection Systems (Applied Biosystems, Foster City). Genotype data were read blind to the WAIS-R scores. Ambiguous genotype data were not included in the analysis.

\subsection{Statistical analysis}

Categorical variables were compared using $\chi^{2}$ test. Mean differences between groups were assessed by analysis of variance (ANOVA). Differences in the WAIS-R scores between the genotypes were also tested using analysis of covariance (ANCOVA), with age, gender, and years of education as covariates. Scaled scores were used in the analysis of the subtest scores. Post hoc tests were performed using Bonferroni's correction for multiple comparisons. Associations between age and the subtest raw 
scores were examined with a linear regression analysis. The difference between two regression coefficients was estimated by calculating the t value. Statistical analyses were performed using the statistical package for the social sciences (SPSS) version 11.0 (SPSS Japan, Tokyo). Statistical tests were two tailed and statistical significance was considered when $\mathrm{P}<0.05$.

\section{Results}

The number of subjects, age, years of education, and the WAIS-R scores for each genotype are presented in Table 1. The genotype frequencies of the subjects were not significantly deviated from Hardy-Weinberg equilibrium $\left(\chi^{2}=2.3\right.$, df $\left.=1, P=0.13\right)$. Gender distribution did not significantly differ across genotypes $\left(\chi^{2}=2.1\right.$, df $=2, \mathrm{P}=$ 0.35). The WAIS-R full-scale intelligence quotient (FIQ) ranged from 74 to 143 (average \pm s.d. $=111.6 \pm 11.9)$. ANOVA analyses revealed significant differences in mean verbal IQ (VIQ) and three verbal subtest scores (information, vocabulary, and similarities) between the genotypic groups. These differences remained significant even when age, gender, and years of education were controlled for in the ANCOVA analyses. However, there was no significant difference in performance IQ (PIQ), full-scale IQ, or any of the performance subtest scores across the three genotypic groups.

As shown in Table 1, subjects homozygous for the Asp allele showed better performance in VIQ and verbal subtest scores, compared with those carrying the Ala allele (i.e, individuals with a genotype of Asp/Ala or Ala/Ala). When genotypes were thus dichotomized into carriers and non-carriers of the Ala allele, the latter showed 
significantly higher VIQ compared to the former $(\mathrm{F}=7.9, \mathrm{df}=1,567, \mathrm{P}=0.005$, by ANCOVA). Non-carriers of the Ala allele scored significantly higher than the carriers in information $(\mathrm{F}=10.0, \mathrm{df}=1,567, \mathrm{P}=0.0017)$, vocabulary $(\mathrm{F}=6.4, \mathrm{df}=1,567, \mathrm{P}=0.012)$, and similarities $(\mathrm{F}=6.1, \mathrm{df}=1,567, \mathrm{P}=0.014)$ subtests controlling for age, gender, and years of education. When analyzed separately in two age groups, i.e. below and above 50 years old $(\mathrm{N}=348$ and 228, respectively), the scores of these subtests were higher in Ala non-carriers compared to carriers in both age groups but the difference reached statistical significance in only the older group $(\mathrm{P}=0.0048, \mathrm{P}=0.0057, \mathrm{P}=0.010$, and $\mathrm{P}=0.024$ for VIQ, information, vocabulary, and similarities, respectively).

Age was significantly negatively correlated with the raw scores of every subtest except for information, vocabulary, and comprehension in each genotype group. Conversely, information and vocabulary scores showed significant positive correlation with age in Asp/Asp group, as shown in Table 2(A). Regression coefficients were significantly higher in Asp homozygotes compared to Ala homozygotes in these subtests (Table 2(B)).

\section{Discussion}

Our results suggest that the Asp358Ala polymorphism of the IL-6R gene is associated with some aspects of cognitive functioning in healthy adults. In particular, three of the verbal subtest scores and the total VIQ were lower in carriers of the Ala allele compared to non-carriers. Since the Ala allele is strongly associated with higher IL-6 and sIL-6R levels (Galicia et al. 2004; Rafiq et al. 2007; Reich et al. 2007; Jiang et 
al. 2010; Sasayama et al. 2011b), our findings support the possibility that excessive IL-6 signaling may have a negative impact on cognitive ability.

Some previous studies have shown that genetic variations in the gene encoding IL-1 $\beta$, which stimulates IL-6 production (Van Damme et al. 1987), may be associated with cognitive performance (Baune et al. 2008; Tsai et al. 2010; Sasayama et al. 2011a). The present study showed for the first time, to our knowledge, that the IL-6R gene variation is also associated with cognitive performance, further supporting the involvement of pro-inflammatory genes in modulating cognitive function.

Our data indicated that Asp homozygotes performed better than Ala carriers in subtests requiring examinees to use long-term memory stores, such as information and vocabulary. Separate analyses in two age groups suggested that the difference was greater in those above 50 years old. Furthermore, these subtest raw scores were positively correlated with age in only Asp homozygotes. These findings suggest that Asp homozygotes have higher ability to transfer information into the long-term memory store, resulting in greater difference in built-up knowledge compared to Ala carriers as they age. On the other hand, we obtained no evidence for association between the polymorphism and score of subtests requiring working memory, such as digit span and arithmetic. These findings may suggest that excessive IL-6 signaling due to the Asp358Ala polymorphism has a negative impact on acquisition/retention of knowledge rather than the short-term memory function. This may partly be explained by the impairment in hippocampal-dependent learning and memory related to IL-6. A number of animal studies have shown that IL-6 inhibits LTP in the hippocampus (Bellinger et al. 
1995; Tancredi et al. 2000; Li et al. 1997). These findings raise the possibility that constantly elevated IL-6 signaling in Ala carriers may have impaired the acquisition of new memories. Future studies are necessary to confirm our findings by prospectively examining the longitudinal effects of the Asp358Ala polymorphism on acquiring cognitive ability requiring long-term memory.

\section{Acknowledgements}

This study was supported by Health and Labor Sciences Research Grants (Comprehensive Research on Disability, Health, and Welfare), Grant-in-Aid for

Scientific Research from the Japan Society for the Promotion of Science (JSPS), Core Research of Evolutional Science \& Technology (CREST), Japan Science and Technology Agency (JST), the Strategic Research Program for Brain Sciences by the Ministry of Education, Culture, Sports, Science and Technology of Japan (Understanding of molecular and environmental bases for brain health), and Intramural Research Grant for Neurological and Psychiatric Disorders of NCNP (H.K.). 


\section{References}

American Psychiatric Association (1994) DSM-IV: Diagnostic and Statistical Manual of Mental Disorders. 4th edition. American Psychiatric Press, Washington D.C.

Baune BT, Ponath G, Rothermundt M, Riess O, Funke H, Berger K (2008) Association between genetic variants of IL-1beta, IL-6 and TNF-alpha cytokines and cognitive performance in the elderly general population of the MEMO-study. Psychoneuroendocrinology 33 (1):68-76

Bellinger FP, Madamba SG, Campbell IL, Siggins GR (1995) Reduced long-term potentiation in the dentate gyrus of transgenic mice with cerebral overexpression of interleukin-6. Neurosci Lett 198 (2):95-98

Braida D, Sacerdote P, Panerai AE, Bianchi M, Aloisi AM, Iosue S, Sala M (2004) Cognitive function in young and adult IL (interleukin)-6 deficient mice. Behav Brain Res 153 (2):423-429

Galicia JC, Tai H, Komatsu Y, Shimada Y, Akazawa K, Yoshie H (2004) Polymorphisms in the IL-6 receptor (IL-6R) gene: strong evidence that serum levels of soluble IL-6R are genetically influenced. Genes Immun 5 (6):513-516

Heyser CJ, Masliah E, Samimi A, Campbell IL, Gold LH (1997) Progressive decline in 
avoidance learning paralleled by inflammatory neurodegeneration in transgenic mice expressing interleukin 6 in the brain. Proc Natl Acad Sci U S A 94 (4):1500-1505

Huberman M, Sredni B, Stern L, Kott E, Shalit F (1995) IL-2 and IL-6 secretion in dementia: correlation with type and severity of disease. J Neurol Sci 130 (2):161-164

Jiang CQ, Lam TH, Liu B, Lin JM, Yue XJ, Jin YL, Cheung BM, Thomas GN (2010) Interleukin-6 receptor gene polymorphism modulates interleukin-6 levels and the metabolic syndrome: GBCS-CVD. Obesity (Silver Spring) 18 (10):1969-1974

Lekander M, Von Essen J, Schultzberg M, Andreasson AN, Garlind A, Hansson LO, Nilsson LG (2011) Cytokines and memory across the mature life span of women. Scand J Psychol: doi: 10.1111/j.1467-9450.2010.00865.x.

Li AJ, Katafuchi T, Oda S, Hori T, Oomura Y (1997) Interleukin-6 inhibits long-term potentiation in rat hippocampal slices. Brain Res 748 (1-2):30-38

Marsland AL, Gianaros PJ, Abramowitch SM, Manuck SB, Hariri AR (2008) Interleukin-6 covaries inversely with hippocampal grey matter volume in 
middle-aged adults. Biol Psychiatry 64 (6):484-490

Marsland AL, Petersen KL, Sathanoori R, Muldoon MF, Neumann SA, Ryan C, Flory JD, Manuck SB (2006) Interleukin-6 covaries inversely with cognitive performance among middle-aged community volunteers. Psychosom Med 68 (6):895-903

Otsubo T, Tanaka K, Koda R, Shinoda J, Sano N, Tanaka S, Aoyama H, Mimura M, Kamijima K (2005) Reliability and validity of Japanese version of the Mini-International Neuropsychiatric Interview. Psychiatry Clin Neurosci 59 (5):517-526

Rafiq S, Frayling TM, Murray A, Hurst A, Stevens K, Weedon MN, Henley W, Ferrucci L, Bandinelli S, Corsi AM, Guralnik JM, Melzer D (2007) A common variant of the interleukin 6 receptor (IL-6r) gene increases IL-6r and IL-6 levels, without other inflammatory effects. Genes Immun 8 (7):552-559

Reich D, Patterson N, Ramesh V, De Jager PL, McDonald GJ, Tandon A, Choy E, Hu D, Tamraz B, Pawlikowska L, Wassel-Fyr C, Huntsman S, Waliszewska A, Rossin E, Li R, Garcia M, Reiner A, Ferrell R, Cummings S, Kwok PY, Harris T, Zmuda JM, Ziv E (2007) Admixture mapping of an allele affecting interleukin 6 
soluble receptor and interleukin 6 levels. Am J Hum Genet 80 (4):716-726

Sasayama D, Hori H, Teraishi T, Hattori K, Ota M, Matsuo J, Kawamoto Y, Kinoshita Y,

Higuchi T, Amano N, Kunugi H (2011a) Association of interleukin-1beta genetic

polymorphisms with cognitive performance in elderly females without dementia.

J Hum Genet. doi:10.1038/jhg.2011.56

Sasayama D, Wakabayashi C, Hori H, Teraishi T, Hattori K, Ota M, Ishikawa M, Arima

K, Higuchi T, Amano N, Kunugi H (2011b) Association of plasma IL-6 and

soluble IL-6 receptor levels with the Asp358Ala polymorphism of the IL-6

receptor gene in schizophrenic patients. J Psychiatr Res.

doi:10.1016/j.jpsychitres.2011.06.003

Sheehan DV, Lecrubier Y, Sheehan KH, Amorim P, Janavs J, Weiller E, Hergueta T,

Baker R, Dunbar GC (1998) The Mini-International Neuropsychiatric Interview

(M.I.N.I.): the development and validation of a structured diagnostic psychiatric interview for DSM-IV and ICD-10. J Clin Psychiatry 59 Suppl 20:22-33;quiz

$34-57$

Shinagawa F, Kobayashi S, Fujita K, Maekawa H (1990) Japanese Wechsler Adult

Intelligence Scale-Revised. Nihon Bunka Kagakusha, Tokyo 
Singh VK, Guthikonda P (1997) Circulating cytokines in Alzheimer's disease. J Psychiatr Res 31 (6):657-660

Tancredi V, D'Antuono M, Cafe C, Giovedi S, Bue MC, D'Arcangelo G, Onofri F, Benfenati F (2000) The inhibitory effects of interleukin-6 on synaptic plasticity in the rat hippocampus are associated with an inhibition of mitogen-activated protein kinase ERK. J Neurochem 75 (2):634-643

Tsai SJ, Hong CJ, Liu ME, Hou SJ, Yen FC, Hsieh CH, Liou YJ (2010) Interleukin-1 beta $(\mathrm{C}-511 \mathrm{~T})$ genetic polymorphism is associated with cognitive performance in elderly males without dementia. Neurobiol Aging 31 (11):1950-1955

Van Damme J, Opdenakker G, Simpson RJ, Rubira MR, Cayphas S, Vink A, Billiau A, Van Snick J (1987) Identification of the human 26-kD protein, interferon beta 2 (IFN-beta 2), as a B cell hybridoma/plasmacytoma growth factor induced by interleukin 1 and tumor necrosis factor. J Exp Med 165 (3):914-919

Weaver JD, Huang MH, Albert M, Harris T, Rowe JW, Seeman TE (2002) Interleukin-6 and risk of cognitive decline: MacArthur studies of successful aging. Neurology 59 (3):371-378

Wechsler D (1981) The Wechsler Adult Intelligence Scale-Revised. The Psychological 


\section{Corporation, San Antonio}

Yaffe K, Lindquist K, Penninx BW, Simonsick EM, Pahor M, Kritchevsky S, Launer L,

Kuller L, Rubin S, Harris T (2003) Inflammatory markers and cognition in well-functioning African-American and white elders. Neurology 61 (1):76-80 
Table 1: The number of subjects, age, years of education, and WAIS-R scores for each genotype of the Asp358Ala polymorphism of the IL-6R gene

\begin{tabular}{|c|c|c|c|c|c|c|}
\hline & \multirow{2}{*}{ Asp/Asp } & \multirow{2}{*}{ Asp/Ala } & \multirow{2}{*}{ Ala/Ala } & \multirow{2}{*}{ Total } & \multicolumn{2}{|c|}{ Statistical analysis $^{(\mathrm{a})}$} \\
\hline & & & & & F value & P value \\
\hline N (Male/Female) & $186(51 / 135)$ & $298(67 / 231)$ & $92(26 / 66)$ & $576(144 / 432)$ & & \\
\hline Age (years) & $45.1 \pm 15.5$ & $44.0 \pm 14.8$ & $48.4 \pm 14.3$ & $45.1 \pm 15.0$ & 3.03 & 0.049 \\
\hline Education (years) & $15.1 \pm 2.6$ & $15.0 \pm 2.7$ & $14.8 \pm 3.0$ & $15.0 \pm 2.7$ & 0.43 & 0.65 \\
\hline \multicolumn{7}{|l|}{ WAIS-R } \\
\hline \multicolumn{7}{|l|}{ Verbal subtests } \\
\hline Information & $11.7 \pm 2.6$ & $11.0 \pm 2.8$ & $11.0 \pm 2.8$ & $11.2 \pm 2.8$ & 5.523 & 0.004 \\
\hline Digit span & $11.6 \pm 3.0$ & $11.2 \pm 2.8$ & $11.7 \pm 2.6$ & $11.4 \pm 2.8$ & 1.765 & 0.17 \\
\hline Vocabulary & $12.1 \pm 2.6$ & $11.4 \pm 2.7$ & $11.5 \pm 2.9$ & $11.7 \pm 2.7$ & 3.356 & 0.036 \\
\hline Arithmetic & $11.3 \pm 2.9$ & $11.0 \pm 3.0$ & $10.9 \pm 3.1$ & $11.1 \pm 3.0$ & 0.804 & 0.45 \\
\hline Comprehension & $11.7 \pm 2.8$ & $11.5 \pm 2.8$ & $11.5 \pm 2.9$ & $11.6 \pm 2.8$ & 0.387 & 0.68 \\
\hline Similarities & $12.8 \pm 2.1$ & $12.2 \pm 2.4$ & $12.3 \pm 2.4$ & $12.4 \pm 2.3$ & 3.042 & 0.049 \\
\hline \multicolumn{7}{|l|}{ Performance subtests } \\
\hline Picture completion & $10.4 \pm 2.4$ & $10.6 \pm 2.2$ & $10.8 \pm 2.4$ & $10.5 \pm 2.3$ & 0.434 & 0.65 \\
\hline Picture arrangement & $11.3 \pm 2.6$ & $11.4 \pm 2.6$ & $11.7 \pm 2.9$ & $11.4 \pm 2.7$ & 0.368 & 0.69 \\
\hline Block design & $12.3 \pm 2.7$ & $12.1 \pm 3.2$ & $12.0 \pm 2.8$ & $12.2 \pm 3.0$ & 0.209 & 0.81 \\
\hline Object assembly & $11.6 \pm 2.9$ & $11.4 \pm 3.0$ & $10.9 \pm 3.1$ & $11.4 \pm 3.0$ & 1.100 & 0.33 \\
\hline Digit symbol & $13.3 \pm 2.8$ & $13.1 \pm 2.5$ & $13.8 \pm 2.8$ & $13.2 \pm 2.7$ & 2.113 & 0.12 \\
\hline VIQ & $112.4 \pm 12.1$ & $109.0 \pm 12.8$ & $109.6 \pm 12.4$ & $110.2 \pm 12.6$ & 4.008 & 0.019 \\
\hline PIQ & $111.4 \pm 12.1$ & $110.9 \pm 11.8$ & $111.5 \pm 12.7$ & $111.1 \pm 12.0$ & 0.032 & 0.97 \\
\hline FIQ & $113.1 \pm 11.6$ & $110.8 \pm 11.8$ & $111.4 \pm 12.6$ & $111.6 \pm 11.9$ & 1.588 & 0.21 \\
\hline
\end{tabular}

Data are presented as mean \pm standard deviation. P values $<0.05$ are shown in boldface.

(a) Age and years of education were assessed with ANOVA.

WAIS-R scores were assessed with ANCOVA adjusted for gender, age, and years of education

IL-6R: interleukin-6 receptor; ANOVA: analysis of variance; ANCOVA: analysis of covariance;

WAIS-R: Wechsler adult intelligence scale-revised; VIQ: verbal intelligence quotient; PIQ: performance intelligence quotient;

FIQ: full scale intelligence quotient 
Table 2: Results of the linear regression analyses in each genotype group with age as the independent variable and subtest scores associated with Asp358Ala genotype as dependent variables

\begin{tabular}{|c|c|c|c|c|c|c|c|c|c|c|c|c|c|c|}
\hline \multirow{2}{*}{$\begin{array}{c}\text { Asp358Ala } \\
\text { genotype }\end{array}$} & \multirow{2}{*}{$\mathrm{N}$} & \multirow{2}{*}{ Variable } & \multicolumn{4}{|c|}{ Information } & \multicolumn{4}{|c|}{ Vocabulary } & \multicolumn{4}{|c|}{ Similarities } \\
\hline & & & $\beta$ & $95 \% \mathrm{CI}$ & $\mathrm{PV}$ & alue & $\beta$ & $95 \% \mathrm{CI}$ & \multicolumn{2}{|c|}{$\mathrm{P}$ value } & $\beta$ & $95 \% \mathrm{CI}$ & \multicolumn{2}{|c|}{ P value } \\
\hline \multirow{2}{*}{ Asp/Asp } & \multirow{2}{*}{186} & \multirow{2}{*}{$\begin{array}{c}\text { Intercept } \\
\text { Age }\end{array}$} & 16.1 & 14.1 to 18.1 & \multicolumn{2}{|c|}{$<0.001$} & 35.1 & 30.3 to 39.9 & \multicolumn{2}{|c|}{$<0.001$} & 22.7 & 21.1 to 24.4 & \multicolumn{2}{|c|}{$<0.001$} \\
\hline & & & 0.061 & 0.019 to 0.10 & \multicolumn{2}{|c|}{0.0046} & 0.133 & 0.032 to 0.234 & \multicolumn{2}{|c|}{0.010} & -0.068 & -0.103 to -0.034 & \multicolumn{2}{|c|}{$<0.001$} \\
\hline \multirow{2}{*}{ Asp/Ala } & \multirow{2}{*}{298} & Intercept & 16.7 & 14.9 to 18.4 & \multicolumn{2}{|c|}{$<0.001$} & 36.9 & 32.9 to 40.9 & \multicolumn{2}{|c|}{$<0.001$} & 23.3 & 21.9 to 24.8 & \multicolumn{2}{|c|}{$<0.001$} \\
\hline & & Age & 0.022 & -0.016 to 0.060 & \multicolumn{2}{|c|}{0.26} & 0.033 & -0.053 to 0.118 & \multicolumn{2}{|c|}{0.46} & -0.101 & -0.133 to -0.069 & \multicolumn{2}{|c|}{$<0.001$} \\
\hline \multirow{2}{*}{ Ala/Ala } & \multirow{2}{*}{92} & Intercept & 18.9 & 15.2 to 22.5 & \multirow{2}{*}{\multicolumn{2}{|c|}{$\begin{array}{c}<\mathbf{0 . 0 0 1} \\
0.40 \\
\end{array}$}} & 42.2 & 33.8 to 50.6 & \multirow{2}{*}{\multicolumn{2}{|c|}{$\begin{array}{c}<\mathbf{0 . 0 0 1} \\
0.34 \\
\end{array}$}} & 24.1 & 21.1 to 27.2 & \multirow{2}{*}{\multicolumn{2}{|c|}{$\begin{array}{l}<0.001 \\
<0.001 \\
\end{array}$}} \\
\hline & & Age & -0.031 & -0.10 to 0.042 & & & -0.081 & -0.247 to 0.086 & & & -0.119 & -0.180 to -0.059 & & \\
\hline \multicolumn{15}{|c|}{ 3) The difference between regression coefficients obtained in each genotype group } \\
\hline \multirow{2}{*}{\multicolumn{3}{|c|}{$\begin{array}{c}\text { Asp358Ala } \\
\text { genotype }\end{array}$}} & \multicolumn{4}{|c|}{ Information } & \multicolumn{4}{|c|}{ Vocabulary } & \multicolumn{4}{|c|}{ Similarities } \\
\hline & & & $\left|\beta_{2}-\beta_{1}\right|$ & $95 \% \mathrm{CI}$ & t value & P value & $\left|\beta_{2}-\beta_{1}\right|$ & $95 \% \mathrm{CI}$ & t value & $\mathrm{P}$ value & $\left|\beta_{2}-\beta_{1}\right|$ & $95 \% \mathrm{CI}$ & t value & P value \\
\hline $\mathrm{Asp} / \mathrm{Asp}$ & Vs $A$ & sp/Ala & 0.039 & -0.018 to 0.097 & 1.34 & 0.18 & 0.100 & -0.033 to 0.233 & 1.48 & 0.14 & -0.607 & -2.88 to 1.67 & 0.52 & 0.60 \\
\hline Asp/Ala & vs $A$ & la/Ala & 0.052 & -0.029 to 0.133 & 1.27 & 0.20 & 0.113 & -0.070 to 0.296 & 1.22 & 0.22 & -1.410 & -4.78 to 1.96 & 0.84 & 0.40 \\
\hline Ala/Ala & vs A & $\mathrm{p} / \mathrm{Asp}$ & 0.092 & 0.012 to 0.172 & 2.26 & 0.025 & 0.213 & 0.024 to 0.403 & 2.22 & 0.027 & -0.607 & -3.91 to 2.70 & 0.47 & 0.64 \\
\hline
\end{tabular}

$\overline{\mathrm{P} \text { values }<0.05 \text { are shown in boldface. }}$

$95 \%$ CI: $95 \%$ confidence interval 